\title{
LIMA, UMA CIDADE ENTRE A ARISTOCRACIA E A PLEBE (1950-1980)
}

\author{
Marcos Sorrilha Pinheiro*
}

\section{Resumo}

A cidade de Lima passou por sérias transformações ao longo dos últimos sessenta anos. Até meados do século passado, Lima guardava uma estrutura urbanística semelhante àquela construída ainda no final do século XVIII já nas últimas décadas de seu período colonial. Tal realidade começou a se transformar com o início abrupto dos fluxos migratórios serra-costa em 1946. No entanto, mais do que alterações em seu plano urbanístico, Lima passou por uma reconfiguração étnica e social que dariam novas cores e novos padrões comportamentais e culturais à capital peruana. A chegada do migrante à cidade provocou a reação conservadora da elite local, mas também despertou na intelectualidade a necessidade de se elaborar novas formas de se pensar o lugar do migrante no espaço citadino e, de outra forma, criar novas representações sobre a própria cidade. De uma cidade isolada do restante de seu território nacional, Lima passou a conviver com uma gama de referenciais culturais e étnicos, no entanto, sem ceder maiores espaços para a integração de suas massas à sua lógica urbana e social, deixando claro a separação existente entre sua aristocracia e sua plebe.

Palavras-chave: Lima. Migrações. Ciências Sociais.

Uma cidade se define por seus habitantes, suas edificações, a maneira de organizar seus espaços, suas ruas e praças, porém uma cidade é também a forma como imaginam aqueles que a visitam.

(FLORES GALINDO)

\section{A Capital Estrangeira}

Ao longo de mais de cinco séculos, Lima foi descrita e representada por uma gama de personagens: viajantes, pintores, comerciantes, diplomatas e outros tantos homens de penas e

\footnotetext{
* Marcos Sorrilha Pinheiro é Professor Assistente Doutor do Departamento de História da Universidade Estadual Paulista (Unesp-Franca). Email: jaca_rp@yahoo.com.
} 
pincéis. Em aquarelas, afrescos ou trovas, do Vice-Reinado colonial aos tumultuados anos 1980, a cidade despertou paixões e ódios fervorosos em seus observadores. Ainda no início do século XIX, o poeta norte-americano Herman Melville chegou a afirmar que se tratava da cidade mais triste que se poderia ver em todo mundo.

Quiçá as observações feitas pelo naturalista alemão Alexander Von Humboldt, em sua passagem pelo país andino, nos ajudem a explicar o descontentamento de seu contemporâneo. Afinal, as correntes marítimas que levam o seu nome desfavorecem a ocorrência de fartas chuvas - o que faz desnecessária a presença de telhados suntuosos e coberturas decorativas nas casas -, deixa o céu constantemente nublado e a paisagem com um panorama desértico e sem muita variedade de vegetação. Até os dias de hoje é comum ouvir dos próprios limenhos que o céu da cidade se assemelha a uma grande panza de burro, pelo tom cinzento predominante. Além disso, de uma forma mais poética, afirma-se que o céu gris inspira a tristeza de seus citadinos.

Os constantes abalos sísmicos também poderiam explicar tamanha insatisfação quanto às belezas arquitetônicas. Para produzir uma acomodação das estruturas e não haver grandes perdas com os tremores de terra, até o final do século XIX as construções eram erguidas preferencialmente com madeira, tijolos de barro e cana de açúcar. Assim, ter uma casa bela e vistosa não foi a opção da aristocracia local para ostentar sua riqueza e distinção social. Ainda que tenham existido casarões de mil metros quadrados com mais de quarenta cômodos, como a casona de Martín de Osambela na "Lima Velha”, a elite local preferiu investir em aquarelas, espetáculos públicos e no acúmulo de pratarias e jóias para exibirem sua notoriedade.

Independentemente de quais sejam suas motivações, climáticas ou estéticas, essas denominações depreciativas se repetiram vastamente em vários outros momentos e acabaram se consagrando no ensaio do escritor peruano Salazar Bondy de 1964, intitulado Lima La Horrible $^{1}$. No entanto, devemos ressaltar que o texto de Bondy, que consta como um dos cinquenta livros que todo peruano culto deve ler (ALVOJIN; HERNANDEZ; SAGASTI, 2000), não foi escrito apenas como referência aos padrões arquitetônicos da cidade, mas, principalmente, como resposta ao sentimento nostálgico das elites peruanas diante das transformações urbanísticas e culturais causadas pela chegada de novos atores sociais à capital peruana.

Chamada por Bolívar de “a cidade à deriva” no início do século XIX, desde a época colonial Lima parecia um lugar que não pertencia ao Peru. Sua busca por refutar o espaço

\footnotetext{
${ }^{1}$ A designação Lima la Horrible para a cidade foi cunhada em 1949 em um poema do pintor e poeta Cesar Moro. Mas imortalizou-se na obra de Salazar Bondy.
} 
geográfico e cultural ao qual se inseria gerou para si codinomes como: Cidade dos Reis e a Capital Estrangeira. Tal desconexão com sua realidade espacial fez com que o vice-reinado do Peru ficasse conhecido por produzir uma nítida diferenciação entre a capital (República dos Espanhóis) e a serra (República dos Índios e suas missões). Estranhamente, para muito além dos novecentos, o Peru manteve esta imagem de divisão cultural e geográfica bastante definida até meados do século XX. No entanto, algumas transformações estruturais vividas pela sociedade peruana por esta época conduziram à deformação de tal quadro.

Emblematicamente, podemos afirmar que o "Castelo de Toledo" começou seu desmoronamento no final da década de 1940 e não foi resultado de nenhum dos célebres terremotos que assolam a capital peruana desde que se tem o mais remoto relato colhido por padres e viajantes em suas crônicas. Na realidade as mudanças foram provocadas por uma avalanche. Uma avalanche oriunda de vários pontos da cordilheira dos Andes em direção ao litoral. Porém o desmoronamento violento e rápido vindo das montanhas andinas não era composto por neve, mas sim por homens e mulheres que chegavam às portas da cidade em busca de trabalho e melhores condições de vida. Rapidamente, as margens da velha Lima e seus balcões coloniais foram sendo preenchidos por bolsões populacionais com um colorido peculiar dos tecidos, tendas e roupas andinas e por um tom mais moreno de pele. A formação de vilas, filas e favelas provocaram uma reação imediata de setores da elite que rotularam negativamente a nova paisagem da capital. Os novos bairros que se formavam da noite para o dia passaram a ser denominados pejorativamente de barriadas e os novos integrantes do espaço urbano, caracterizados como cholos.

\section{A “invasão” andina}

O primeiro sinal desse abrupto deslocamento populacional foi dado ainda no ano de 1946 em uma região denominada Cerro de Sán Cosme no distrito de La Victoria. Na oportunidade, cerca de cem famílias oriundas em sua maioria das cidades de Ayacucho, Junin, Ancash, Huancavelica e La Liberta, apareceram subitamente instaladas em barracos e casas improvisadas naquela localidade ${ }^{2}$. O evento seria apenas o primeiro de um fenômeno constante na cidade limenha até o início da década de 1970. Apenas nos primeiros dez anos, o número de barriadas estendeu-se para 30, o equivalente a cerca de 200 mil novos migrantes

\footnotetext{
${ }^{2}$ Desde então, o surgimento repentino de novas barriadas não deixou de ser constante. No entanto, o caso mais impactante foi o surgimento do distrito de Comas em 1958. Em menos de 48 horas cerca de 10.000 novas pessoas ocuparam o lugar Cf. SOARES, Gabriela Pellegrino. Projetos Políticos de Modernização e Reforma no Peru: 1950-1975. São Paulo: Annablume/FAPESP, 2000.
} 
em Lima. Em pouco mais de doze anos a cidade passaria de 1 milhão para 2 milhões de habitantes ${ }^{3}$.

Existem alguns fatores que nos ajudam explicar a explosão migratória para a cidade de Lima naquele momento. Entre eles, começaremos apontando a melhora nos serviços de saúde e a expansão da oferta de medicamentos. A introdução de remédios como a penicilina, a sulfa e a cortisona, bem como a extensão da rede pública de saúde possibilitaram um crescimento populacional jamais visto anteriormente. Entre 1940 e 1971, a mortalidade infantil caiu de 27 para 11 por mil, enquanto a natalidade oscilou de 45 para 42 por mil, o que deu espaço a uma explosão demográfica que se verificaria mais precisamente a partir da década de 1950 (cf. CONTRERAS; CUETO, 2007).

O crescimento populacional nas regiões andinas provocou um aumento inevitável também em sua capacidade de produzir mão de obra para o trabalho. No caso peruano, até então um típico país agrário e rural, resultou na "produção” de novos e mais camponeses. Consequentemente, isto implicou diretamente em problemas para a organização social nos Andes peruanos. Ao contrário do que pode sugerir uma leitura generalista da História da América Latina, o Peru não foi um caso típico de reformas modernizadoras em sua estrutura produtiva no início do século XX. Diferente de vários países como o Brasil de Vargas, o México de Cárdenas, o Chile de Alessandri e, mais tardiamente, a Argentina de Perón, no Peru, a década de 1930 não foi marcada pela “onda modernizadora”. Inversamente, a crise econômica mundial de 1929 acertou em cheio as pretensões de modernização do presidente Augusto Leguía (1919-1930) que, deposto do cargo de Presidente da República por forças conservadoras, deu espaço para o fortalecimento da oligarquia tradicional garantida pelo braço forte dos militares.

A partir de então, a oligarquia conseguiu se manter no poder por meio de golpes e acordos estabelecidos com diversificados setores da sociedade peruana que durariam até o início da década de 1960. Para aquilo que aqui nos interessa, podemos dizer que a manutenção da aristocracia oligárquica no comando das ações políticas peruanas, gerou um quadro de estagnação econômica e uma baixa diversificação nas maneiras de se produzir, bem como na cesta de produtos elaborados pelo Peru. Destarte, a falta de incorporação de técnicas

\footnotetext{
${ }^{3}$ Lima foi o destino mais certo para as migrações. Porém, elas foram um fenômeno nacional. A partir da década de 1950 registrou-se o crescimento de quase todas as principais cidades do Peru e não somente Lima. Alguns exemplos de crescimento urbano entre as décadas de 1940 e 1990: Cuzco, de 486.592 para 1.028.763 hab.; Arequipa, de 263.077 para 916.806 hab.; Puno, de 548.371 para 1.079.849 hab.; Lima, de 828.298 para 6.386.308 hab. Cf. CONTRERAS, Carlos; CUETO, Marcos. Historia del Perú contemporáneo. 4. ed. Lima: IEP, 2007. Porém, o fenômeno das barriadas é algo muito característico da capital peruana e não pode ser facilmente encontrado em outros lugares, como demonstra os estudos de José Maria Arguedas sobre a cidade de Chimbote.
} 
avançadas de plantio gerou a criação de um farto excedente de mão de obra nas plantações de algodão e açúcar do país, causando desemprego em larga escala, subempregos e baixos salários no campo. O mundo camponês começava a dissolver-se e a lógica do emprego e da sobrevivência os empurrava em direção à capital ${ }^{4}$. O Peru, país que se acreditava dividido em dois mundos bem distintos, a costa (o urbano - representação do moderno ou da civilização) e a serra (o campo - representação do atraso ou da tradição), começava a apagar suas barreiras geográficas e imaginárias.

É bem verdade que as migrações iniciadas no final da década de 1940 não foram as primeiras a ocorrer no país. Ainda na década de 1920, como reflexo das referidas reformas modernizadoras empreendidas pelo governo de Leguía, os primeiros contingentes de migrantes chegaram a Lima. No entanto, as migrações da década de 1950 foram muito mais impactantes por conta de alguns elementos densamente destacados pelo antropólogo Carlos Franco (1991, p. 193-194):

\begin{abstract}
Em primeiro lugar, pela origem social e até espacial dos migrantes. Eles não pertenciam às elites senhoriais que circundavam as principais capitais e províncias serranas e costeiras que enviaram seus filhos à Lima entre a primeira e segunda década do século. Tampouco pertenciam às classes médias urbanas de comerciantes, profissionais e empregados dessas mesmas capitais e províncias que, entre os anos 30 e 40, incentivaram seus filhos a se dirigirem até a capital. Os migrantes dos anos 50 em diante vieram, em sua vasta maioria, das comunidades camponesas e das famílias de servos, peões, e yanaconas das fazendas situadas nas províncias mais pobres, nos vales interandinos e nos pisos ecológicos mais altos nos Andes. [...] Em segundo lugar, diferentemente das migrações anteriores, a que se inicia nos anos 50 não teve como resultado a concentração exclusiva em Lima, mas se irradia não somente para as principais capitais da costa como também da serra e, na última década, à selva. [...] Uma terceira diferença - e a mais notável - é o contingente extraordinariamente massivo que se dirigiu do campo e dos Andes até Lima e às sedes urbanas do país. Esta migração envolveu literalmente milhões de peruanos no decorrer de duas ou três décadas. Não foi, portanto, um processo episódico, intermitente e minoritário como os anteriores, mas massivo, contínuo e global. Não é sem sentido que se recorra à atemorizada imagem citadina da "invasão" para dar conta de sua magnitude.
\end{abstract}

Como podemos observar no excerto de Franco, a primeira grande marca dessas migrações era a sua composição social formada por membros de setores mais pobres da sociedade rural peruana. Não se tratou, portanto, de um tipo de migração em busca de

\footnotetext{
${ }^{4}$ Além das migrações, outro reflexo do crescimento populacional do campo foi o crescimento de revoltas camponesas reivindicando reforma agrária melhores salários, a distribuição de terras comunitárias, entre outras exigências. As principais revoltas foram aquelas lideradas por Hugo Blanco na região de La Convención em 1962 e pelo MIR em 1965.
} 
formação educacional ou de um melhor posicionamento social junto à elite da capital. Muito pelo contrário. Tratou-se de um tipo de migração massiva, em busca de sobrevivência e sem qualquer respaldo efetivo das autoridades nacionais ou do próprio Estado ${ }^{5}$.

A chegada do migrante não representou apenas a expansão geográfica e demográfica da zona urbana da capital, mas também a inserção de novos elementos culturais em sua sociedade. Segundo Gabriela Pellegrino Soares (2000, p. 17), “tais foram nessa época o ritmo e amplitude das imigrações à capital - cidade cuja identidade, apesar dos vários surtos modernizadores, ainda estava muito presa aos padrões tradicionais imperantes no tempo da colônia - que esta teria o seu perfil rapidamente transformado”. A transformação pela qual passariam o país e a cidade, a partir de então, foi tamanha que o cientista político peruano Alberto Adrianzén (1990, p. 15), chegou a afirmar que o ano de “1950, para muitos peruanos, é um ano quase mágico. [...] chave para a história posterior do país”. Carlos Franco endossa tal afirmação quando concebe que as mudanças trazidas pela migração foram responsáveis pela ruptura histórica mais importante da sociedade peruana do século XX. Para o autor, isso se dá por conta de cinco modificações psicossociais na sociedade peruana assim delimitadas:

a) seu caráter de ruptura da sociedade rural; b) na libertação da subjetividade do determinismo da tradição produzida em milhões de peruanos; c) na constituição de um novo sentido de espaço e tempo; d) na alteração das orientações de valor, padrões comportamentais e estilos culturais de seus protagonistas; e) em sua capacidade de produzir, ou melhor, coproduzir os processos de urbanização, a economia informal, a cultura chola e a organização popular do Peru atual (FRANCO, 1991, p. 198).

Tamanha é a importância que possui este fenômeno que o autor concluiu que, sem a migração da década de 1950 “o Peru atual não poderia reconhecer o seu rosto no espelho dos anos 90” (FRANCO, 1991, p. 198). É importante ressaltarmos que Carlos Franco defende que o processo migratório alterou a sociedade não apenas em seus aspectos organizativos, mas também mentais. Segundo argumenta, a decisão de deixar para trás as terras dos antepassados representou uma ruptura com a maneira tradicional do pensamento andino calcado na ideia do eterno retorno, do tempo cíclico. Ao mesmo tempo, provocou também um desligamento do lugarejo sagrado, representado por uma ideia panteísta e animista de relação com o espaço.

\footnotetext{
${ }^{5}$ Dentre a vasta bibliografia que se dedica ao estudo das migrações peruanas, somente os trabalhos de David Collier discordam da concepção de migrações “espontâneas”. Para o autor, as migrações foram incentivadas por um certo "corporativismo autoritário" que regulou os fluxos de deslocamento de pessoas e até mesmo o incentivou, tendo como consequência a incorporação dos migrantes à lógica do Estado quando estes chegaram ao meio urbano. Ver: COLLIER, David. "Los Pueblos Jóvenes y la Adaptación de los migrantes al ambiente urbano limeño”. In: Estudios Andinos, ano 3, vol III, n. 3, Centro de Estudios Latinoamericanos, Universidad de Pitsburg, 1973 e . Barriadas y Elites. De Odría a Velasco. Lima: IEP, 1978.
} 
Como se as montanhas e os rios abençoados deixassem de ser o único local de proteção e provimento de vida segura e comunitariamente construída. Aos poucos substituiriam o mito do Inkarri pelo mito da modernização em sua forma de conceber seu desenvolvimento econômico e social, individuais e coletivos. Por outro lado, a chegada do migrante à cidade também transformou a maneira como os citadinos passaram a idealizar os Andes. Visto como paisagem longínqua, como a representação do distante e encarnação do que seria o "Peru profundo", a cordilheira andina peruana foi concebida ao longo do tempo, como o local da tradição, do tempo imóvel, por vezes o atraso, e, por outras, a encarnação bucólica e romântica da harmonia entre o homem e a natureza.

A transformação de Lima não foi evidente apenas no crescimento desordenado da cidade e no número cada vez mais volumoso de pessoas nas periferias. O fenômeno das barriadas da década de 1950 produziu também alterações perceptíveis nas manifestações culturais. As músicas andinas ganharam espaço no cotidiano da vida limenha, nos rádios e nos teatros. Como escreveram Carlos Contreras e Marcos Cueto (2007, p. 306),

Precisamente o rádio, junto com o já mencionado fenômeno da migração à capital, deram espaço à aparição nos anos cinquenta das figuras da canção vernácula. O "Jilguero de Huascarán”, o “Zorzal Andino”, o "Picaflor de los Andes", junto com "Flor Pucarina” e muitas outras cantoras, seguiram como símbolos populares em escala nacional. Além de transmitir sua música pelo rádio, enchiam os coliseus das cidades (um tipo de teatro popular) e campos esportivos nos finais de semana.

O rádio, mais do que qualquer outro veículo de comunicação teve um papel fundamental na difusão dos costumes andinos que então envolviam a cidade. $\mathrm{O}$ trabalho do antropólogo José Antonio Lloréns (1990), destaca o quanto os habitantes desses novos bairros se apoiaram em rádios comunitárias para expressar suas demandas e manifestações culturais. Segundo demonstra, a opção pela radiodifusão não teria obedecido somente a questões financeiras ou técnicas, mas também a necessidade de reproduzir no contexto urbano suas identidades regionais. Isto se compreende melhor quando observamos que os novos bairros da capital, ao contrário da desordem sugerida por sua ocupação, eram formados por membros oriundos de uma mesma comunidade andina de partida. Melhor explicando, as barriadas de Lima possuíam correlações com comunidades andinas que procuravam reproduzir, na cidade, a mesma dinâmica social que se encontrava no lugar de partida, desde a divisão do trabalho até o estabelecimento de uma hierarquia política independente daquela existente na capital. Em Lima é comum encontrar nomes de bairros que sejam homônimos de cidades andinas e sua população seja formada por pessoas vindas dali. 
Na organização desta relação entre comunidade de partida e bairro de chegada tiveram destaque especial os clubes de convivência. Os clubes de convivência foram um fator muito importante para compreendermos o estabelecimento desses novos sujeitos à dinâmica da vida citadina. Tais agremiações eram responsáveis não apenas por realizar o contato e a mediação entre os bairros e as comunidades, como também difundir alguns elementos típicos da vida urbana e a da cultura tida por criolla. Como aponta Pablo Sandoval (2000, p. 290),

através de suas organizações regionalistas, os migrantes acumulavam capital social. Desse modo, as associações regionais, não somente seriam espaços de adaptação e/ou reprodução cultural, mas também bases organizativas para a mobilização de recursos políticos que contribuíam para reconfigurar a política urbana, além de incidir na situação social e política dos lugares de origem dos migrantes.

Tal relação de manutenção deste laço com o mundo andino e o papel dos clubes de convivência despertou interesse nos pesquisadores e observadores dos fenômenos das barriadas $^{6}$. De certa forma, assim como a história peruana da década de 1990 não se compreende sem a análise dos fluxos migratórios da década de 1950, o mesmo pode-se dizer sobre o desenvolvimento das ciências humanas e sociais. Várias disciplinas, como a psicologia social, ganharam espaço ou se formularam na tentativa de se compreender as novas relações sociais estabelecidas no espaço urbano. Da mesma forma, a atuação da intelectualidade junto a essas camadas populares foi responsável pelo surgimento de um tipo de intelectual envolvido com as causas sociais urbanas, mesclando militância política com atividade de pesquisa. Tal atuação ficou conhecida como classismo ${ }^{7}$.

De igual feita, outros campos de estudos, como a antropologia, tiveram que desenvolver novas temáticas e novos objetos de pesquisa. Segundo Pablo Sandoval (2000, p. 279), ao aprofundarem-se fundo no estudo deste objeto, os antropólogos ampliaram “os marcos de uma disciplina que havia se especializado em 'outras culturas', distante geográfica e sentimentalmente, mas que ao se encurtar as distâncias começavam a chegar à periferia de Lima”. Em outras palavras, o outro, o indígena e seus rituais nunca estiveram tão próximos.

\footnotetext{
${ }^{6}$ Para saber mais sobre os clubes de convivência e seus estudos ler: ALTAMIRANO, Teófilo. Estructuras Regionales, migración y formación de Asociaciones Regionales en Lima Metropolitana. Lima: PUCP, 1977. JONGKIND, F. “La supuesta funcionalidad de los clubes regionales en Lima, Perú”. In: Boletín de Estudios Latinoamericanos, n. 11, University of Amsterdam, Holanda, 1971. MANGIN, Willian. "Clube de provincianos en Lima”. In: Estudios sobre la Cultura del Perú. Lima: UNMSM, 1964.

${ }^{7}$ Sobre o classismo ver: PINHEIRO, Marcos Sorrilha . A Historiografia Revolucionária: Alberto Flores Galindo e a nueva historia Peruana (1970-1980). Revista Eletrônica da ANPHLAC, v. 9, p. 10, 2010.
} 
O primeiro trabalho antropológico sobre as barriadas de Lima foi o artigo de José Matos Mar (1959) sobre o bairro La Ciudad de Díos intitulado Migración y urbanización. Las barriadas limeñas: un caso de integración a la vida urbana. O texto se inseria nos debates desenvolvidos por um grupo de estudos por ele dirigido e chamado de Proyecto de Estudios de Barriadas, fundado em 1956. As primeiras observações deste grupo, assim como as obras de Matos Mar, indicavam uma dupla conclusão: a chegada da cultura andina a Lima era boa, uma vez que ajudava na difusão de valores comunitários e de solidariedade na capital marcada pelo individualismo capitalista; porém a migração não era um aspecto positivo, uma vez que desequilibrava as cidades, congestionando seus espaços de sociabilidade e provocando um transbordamento populacional ${ }^{8}$.

Esses primeiros estudos tiveram por característica maior o estudo específico da vida nas barriadas e, por conta disso, excluiu-se uma observação mais profunda de como ocorriam as novas relações interpessoais nos espaços públicos próprios da capital. De certa forma, esta abordagem teve como influência o fato de que o migrante, num primeiro momento, não estabeleceu sua residência na velha Lima, mas sim ao seu redor. Não se integrou à cidade, ocupando espaços já construídos e antigos bairros de trabalhadores. Além disso, por conta da manutenção de valores próprios da comunidade de origem, acabaram estabelecendo suas vidas cotidianas dentro de seus próprios bairros. Por conta disso, os trabalhos científicos sobre as barriadas em Lima acabaram estabelecendo uma chave analítica que perdurou até boa parte da década de 1990: a visão de que existe na capital peruana uma divisão clara entre cultura andina e criolla. Na embrionária antropologia urbana de finais da década de 1950, não apenas existia essa determinação, como também foi possível estabelecer juízos de valores entre ambas. Para Sandoval (2000, p. 287),

As investigações antropológicas localizaram dois tipos de culturas na cidade: a andina pujante, progressista e coesa; e a criolla, anômica, desorganizada e individualista. Essas culturas foram localizadas espacialmente nas barriadas e nos tugúrios respectivamente. [...] Ao enfatizar a dualidade cultural andino/criollos nos espaços urbanos, a nascente antropologia ocultava a base estética e moral de suas percepções sobre a cidade.

O que Sandoval sugere é que, esta concepção dualista valorativa obedecia a uma interpretação marxista calcada em interpretações indigenistas de décadas anteriores e, por conta disso, uma visão do andino como a representação de aspectos romanticamente

\footnotetext{
${ }^{8}$ Até os dias de hoje a imagem de uma cidade transbordante é facilmente observável diariamente no transito caótico de Lima e suas incontroláveis buzinas e na ausência de ruas largas no centro da capital, o que aumenta ainda mais a impressão de que existem mais pessoas nas ruas do que pode suportar a Cidade dos Reis.
} 
positivos. Porém, para além os juízos de valores, tais estudos apresentaram a ideia de que Lima, após as migrações, estabeleceu-se como uma cidade cindida, entre criollos/andinos, tugúrios/barriadas, aristocracia/plebe.

De certa forma, esse “desprendimento” do mundo urbano e a autosuficiência das barriadas somente podem ser observados nos anos iniciais à chegada dos primeiros fluxos migratórios. Evidentemente que a política econômica voltada para a agricultura de exportação e de latifúndios não conseguiu gerar, na cidade, empregos suficientes para a nova parte da população que chegava, o que resultou no subemprego e no emprego informal na capital peruana. Assim não demorou em florescer um comércio informal e na abertura de lojas e tendas voltadas para suprir às demandas dessa nova parcela da população. Nas praças localizadas nas redondezas do centro da velha Lima o comércio popular passou a oferecer calçados, roupas, comidas, utensílios domésticos, LPs de 45 rotações com música “folclórica”, entre outros produtos que até então não se encontravam em Lima.

De certa maneira, a formação de uma nova organização social limenha também se refletiu na literatura e nas artes, como nos mostram as obras de José Maria Arguedas e Mario Vargas Llosa, por exemplo. Em 1958, apareceu o livro mais importante de José Maria Arguedas. Intitulada Los Ríos Profundos a obra introduziu, ao grande público, elementos próprios do imaginário sulista dos Andes peruanos, valorizando personagens próprios desta localidade, além de apresentar um panorama dos hábitos, dos costumes, das tradições e dos mitos particulares deste universo.

Em contraposição à valorização e incorporação dos elementos culturais advindos do mundo andino à narrativa de alguns novelistas, surgiram os livros do escritor arequipenho Mario Vargas Llosa. Em obras como La Ciudad y los Perros, de 1962, e La Casa Verde, de 1966, o autor procurou apresentar o que era pensado na cidade, nas classes e setores médios urbanos marginalizados, para além do mundo do migrante, que também se viam mergulhados em valores da tradição religiosa e militar da velha Lima. De certa forma, os romances de Arguedas e Vargas Llosa nos permitem compreender a história dos encontros culturais e a diversidade produzida em Lima, a partir dos anos 1950. A obra de Vargas Llosa, especificamente, atenta-nos para uma questão importante dessa nova sociabilidade que se formava já em meados da década de 1960 com a chegada dos migrantes: os conflitos entre as camadas pobres não andinas e andinas. Por essa época, os tugúrios passaram a ser formados não mais apenas por criollos, mas também por migrantes andinos.

Assim, novas interpretações sobre essas relações estabelecidas entre aristocracia e plebe também começaram a surgir. Já em meados da década de 1960 autores como Aníbal 
Quijano, Julio Cotler, Heraclio Bonilla, Fraçois Bourricaud, entre outros, passaram a dedicar suas atenções aos fenômenos populares que ocorriam em Lima. A melhor representação do pensamento dessas linhas interpretativas foi o termo criado por Aníbal Quijano em sua tese de doutorado de 1965 intitulada La emergencia del grupo cholo y sus implicaciones en la sociedad peruana. Segundo o sociólogo peruano, a década de 1950 marcou o início de um processo de cholificación da capital com a migração serra-costa. Tal processo representava a incorporação da população indígena à realidade da capital e a formação de novos estereótipos sociais, que quebravam as antigas noções de índio, branco e mestiço. O cholo seria "o antigo indígena que graças a sua educação e esforço pessoal, havia ascendido socialmente e realizado uma integração, pelo menos parcial, à sociedade urbana” (CONTRERAS; CUETO, 2007, p. 306). Em outras palavras, cholo é a pessoa de procedência indígena que migrou para a cidade. É uma pessoa que vive nos meios urbanos, mas que possui em seu universo cultural tanto elementos oriundos das tradições andinas de seus antepassados quanto os elementos da modernidade incorporados via cultura urbana.

Conforme esclareceu o próprio Aníbal Quijano (2008) em seu artigo El “movimiento indígena" y las cuestiones pendientes en América Latina, publicado recentemente: “a desindianização da identidade e da autoidentificação de uma parte maior da população ‘índia’, sua ida para as cidades, as atividades vinculadas ao salário e ao mercado, mesmo no mundo rural, [...] foi denominado de 'cholificación’”. Assim, não apenas a cidade cedia espaços às novas culturas, às novas tradições e costumes, mas, também, o migrante ia adaptando-se às exigências e necessidades da vida urbana que se mesclavam aos traços característicos de sua origem. Ainda que a ideia de cholificação da sociedade limenha levasse em conta uma mistura mais efetiva entre setores criollos e andinos, não quer dizer que a dualidade cultural enquanto chave explicativa tenha sido posta de lado. Ao contrário, de um lado se apresentam os cholos, migrantes já adaptados à vida urbana e ao modo de vida criolla e de outro, os próprios criollos limenhos. Neste sentido, a ideia de uma cultura criolla dominante e responsável por estabelecer diretrizes para a vida na cidade ainda persistiu. Mesmo com essa nova roupagem da cholificación, para os estudos deste autor, aristocracia e plebe continuavam apresentadas como chaves interpretativas de Lima.

Se, por um lado, a sociedade limenha passou a conviver e absorver novos referenciais culturais e econômicos em seu dia a dia e em ambientes de aglomeração popular, por outro, a mistura espacial continuou não sendo assim tão clara. Como já afirmamos, tais populações continuaram destinadas em sua grande maioria a uma posição marginal na cidade, como evidencia a disposição geográfica que ocupam as barriadas no plano urbanístico até os dias 
de hoje. Mais, em grande parte, também se desenvolveram a margem do próprio Estado. Assim, o fluxo migratório iniciado na década de 1950 contribuiu para o surgimento não apenas de uma Lima aristocrática e uma Lima plebéia, como também de uma Lima formal e outra Lima informal, o que também seria incorporado pelos estudos sobre a cidade como veremos posteriormente.

De certa forma, esta disposição cindida observável na capital tentou ser dissolvida ao longo da década de 1970. Em 1968 um golpe militar deu início a um tipo de governo autocrático que, surpreendentemente, apresentou como principais metas e projetos políticos algumas das antigas reivindicações das esquerdas peruanas, como a reforma agrária, a industrialização e novas leis trabalhistas. Além disso, houve a preocupação de se construir instrumentos políticos que dialogassem diretamente com as camadas populares dos bairros de periferia, como foi a criação do SINAMOS (Sistema Nacional de Apoyo a la Movilización Social). A intenção do governo com a criação do SINAMOS era estimular a participação popular nas tarefas exigidas para o desenvolvimento econômico. Na realidade, o governo estava preocupado com a aceleração do crescimento da cidade de Lima e de suas barriadas. No início da década de 1970, cerca de 4/5 da população das barriadas não havia nascido em Lima. Essa preocupação resultou no próprio rebatismo das barriadas, que passaram a ser chamadas de pueblos jóvenes, como tentativa de desprender-se do caráter pejorativo que acompanhava o antigo termo.

Na leitura realizada pelos militares, como forma de justificar sua intervenção junto à sociedade civil, as transformações decorridas entre as décadas de 1950 e 1970, por conta da explosão demográfica, tornavam o clima de agitação social muito propício para uma tentativa de revolução popular e de agitamentos sociais. Neste sentido, antes que um golpe revolucionário viesse a desorganizar o status quo político peruano, os militares deveriam agir garantindo a implantação de algumas demandas e reivindicações oriundas dessas mesmas camadas. Por conta disso, várias ações promovidas pelo governo de Velasco Alvarado e do GRFA (Gobierno Revolucionário de las Fuerzas Armadas) atendiam a apelos vindos de setores da esquerda revolucionária peruana - a nacionalização das empresas estrangeiras, o antiamericanismo e a reforma agrária -, da mesma forma que estabeleciam um vínculo forte com as camadas andinas das zonas urbanas - a execução do Plano Estratégico de Reestabelecimento da ordem no país, intitulado Plán Inca; a obrigatoriedade do ensino de quéchua nas escolas e sua transformação em idioma oficial do país; a integração de festas camponesas ao calendário oficial do país; entre outros. Ocorre que, as medidas sociais implantadas pelo GRFA possuíam um alto custo aos cofres públicos e somente puderam ser 
sustentadas enquanto a produção de petróleo nacional garantiu bons lucros ao país. Com a crise do petróleo de meados de 1970, o Estado viu-se obrigado a retirar os subsídios que mantinham certa estabilidade econômica a essas camadas. A partir de 1975, portanto, os problemas relacionados à explosão demográfica voltaram à tona. Porém, com alguns agravantes.

Em 1980, a população peruana já era predominantemente urbana, 57\% contra os 39\% da década de 1960. A maioria dos peruanos era jovem e a relação homem/mulher era equilibrada. Durante a década de 1970, a aceleração do crescimento populacional peruano não diminuiu o ritmo. Foram cerca de 4 milhões de novos habitantes por década, desde 1950. Lima não fugiu à regra e manteve a média aproximada de 1,3 milhões de novos limenhos por decênio. Dessa forma, o Peru, que contava com uma população de 13.538.208 de pessoas no início da década de 1970, chegou ao número de 17.005.210 no início dos anos 1980. Já Lima saiu dos 3.472.564 para 4.745.877 de pessoas no mesmo período.

O primeiro indício de que os problemas da explosão demográfica (a migração serracosta e a posse de terras no campo) não haviam sido resolvidos pela atuação militar veio ainda durante as eleições presidenciais de 1980. Durante as votações no pequeno povoado de Chuschi, localizado ao norte de Ayacucho na região Sul dos Andes, um grupo armado invadiu um colégio eleitoral e ateou fogo nas urnas de votação. Meses depois, os limenhos seriam surpreendidos ao acordarem com um espetáculo sinistro de cães mortos pendurados em postes de energia. Tratavam-se das primeiras ações do Sendero Luminoso. As aparições iniciais senderistas em Lima serviram apenas como aviso ao Estado de que uma mudança vinda do campo estava em marcha. Entre 1980 e 1984, as ações do Sendero Luminoso restringiram-se à região serrana. Os ataques mais fortes à Lima só ocorreriam em meados da década de 1980, no final do segundo governo de Fernando Belaúnde (1980-1985) e início da gestão Alan García (1985-1990).

O outro indício de que as reformas velasquistas haviam falhado foram os números do desemprego e do subemprego em Lima, mais de 50\% dos trabalhadores limenhos para a economia informal. Boa parte dessa parcela era formada por mestiços e indígenas que sofreram com o final da política de subsídios do Estado. Esses eram alguns desafios que marcariam a segunda passagem de Fernando Belaúnde pela presidência da República a partir de 1980. Para conter a crise econômica e tentar superar o dilema do desemprego, Belaúnde retomou tendências liberais de economia e estabeleceu novas leis de mineração e de extração de petróleo, atraindo novos recursos estrangeiros. Contudo, essas medidas eram demasiado 
insuficientes para reverter o estado de calamidade social e absorver a economia informal que tomava conta da cidade de Lima e do Peru de uma forma geral.

Apesar de possuir maioria no Congresso as tentativas de retirar o país da crise esbarraram em outros fatores como

a agonizante dívida externa, a descapitalização e a crise da produção agrária, o peso das instituições e a burocracia pública, a falta de instituições civis no Estado, e a aparição, ao começo subestimada pelo governo, das ações terroristas do Sendero Luminoso (SL) e o Movimento Revolucionário Túpac Amaru (MRTA), que apareceram à luz pública em 1980 e 1984 respectivamente (CONTRERAS; CUETO, 2007, p. 349-350).

A crise da produção agrária era algo que vinha se arrastando desde o final do período de regime militar. Mesmo com a Reforma Agrária que teoricamente deveria garantir o aumento da produção de alimentos, a produção alimentícia não conseguiu acompanhar o crescimento populacional. O clima de convulsão social tomou definitivamente as ruas, os campos e as interpretações das ciências sociais sobre o quadro social, político e econômico do país.

Uma das obras que melhor definiu os quatro primeiros anos de Belaúnde, marcado por distúrbios na cidade e no campo, foi, sem dúvida, Desborde Popular y Crisis del Estado: el nuevo rostro del Perú en la Década de 1980, mais uma vez, de José Matos Mar. O próprio título já sugere a condição da sociedade peruana daquela década. Conforme escreveu o próprio autor

As transformações sofridas pelo Peru, desde a década de 1950, repercutiram recentemente de forma poderosa sobre o balanço e o equilíbrio das relações entre o mundo da oficialidade e o das maiorias, abrindo vias a um novo estilo de revolução. [...] O Peru contemporâneo já não se apresenta como um arquipélago territorial de enclaves urbanos da oficialidade, mais ou menos isolados em um imenso hinterland de marginalidade rural. Lima já não é exclusivamente a capital reduto do criollo e o mestiço monopolizando o poder e a identidade (MATOS MAR, 1988, p. 102-103).

Esse excerto deixa bastante transparente a interpretação do autor no que tange a existência de um novo Peru que extrapolou a imagem oficial que se fazia dele. O novo Peru não era mais a dualidade entre a serra tradicional e a costa moderna. A nova Lima, por sua vez, não era mais o espaço de predomínio da aristocracia, mas sim o lugar da convergência 
peruana, de um Peru real formado pelos constantes anos de migração, pelo andino que vivia na cidade, mas que não conseguia se incorporar formalmente a ela ${ }^{9}$.

Outra importante obra que trata desta relação conflituosa entre a Lima formal e a Lima informal é o livro do economista peruano Hernando de Soto intitulado El Otro Sendero: La revolución invisible en el Tercer Mundo. Em clara alusão ao Sendero Luminoso, El Otro Sendero apontava outro caminho - daí o título - a ser seguido pelo Peru, tendo como palco de análise sua capital. Este caminho seria o do neoliberalismo. Assim como o livro de José Matos Mar, que falava da existência de um país oficial e um país real, em alusão às massas excluídas atiradas à informalidade, o de Soto também apresentou tal quadro. No entanto, sociologicamente a sua abordagem fugiu à linha marxista de análise da realidade, como ocorreu com Matos Mar. Neste caso, o economista, para além da análise, aponta críticas, mas também caminhos para a construção de um novo Peru. Seu principal alvo é o Estado, o modelo estatizante predominante na história recente do país e o excesso de burocracia. Para ele, era preciso implantar um regime com um modelo de estado menor, um estado neoliberal e incentivar a individualidade e o empreendedorismo nos membros da sociedade informal. Analisaremos mais aspectos dessa obra adiante.

Assim como Quijano (sociólogo), Matos Mar (antropólogo) e de Soto (economista), outro importante autor da década de 1980 a analisar a aguda crise existente no Peru e a formação de uma cidade dividida entre o mundo real e o mundo legal foi o historiador Alberto Flores Galindo. O grande diferencial deste autor aos demais está em sua perspectiva de análise do problema por meio do viés da longa duração e das permanências da História. O primeiro trabalho a abordar especificamente esta problemática é justamente aquele que se intitula Aristocracia y Plebe. Lima, 1760 - 1830 de 1984.

O livro possui como objeto de averiguação historiográfica as relações sociais produzidas em Lima entre 1760 e 1830 . Nesse sentido, aborda o período que compreende as últimas décadas do vice-reinado de Lima e os primeiros anos da capital republicana do Peru. Apesar de seus recortes temáticos, o espaço geográfico não se limita apenas à capital e, por isso, personagens e grupos sociais localizados no campo e ao longo da costa também fazem parte da narrativa. Porém, o destaque maior é dado para a análise das “classes sociais” que compunham Lima daquele período. Como apresenta Carlos Aguirre (2007, p. 27), “Aristocracia y Plebe” buscava uma aproximação à complexa realidade social de Lima, por

\footnotetext{
${ }^{9}$ Na mesma época, existiram outras tantas obras que discutiram o tema, como, por exemplo, as reedições e os novos livros de Anibal Quijano, que voltaram a trabalhar a questão da figura do cholo na sociedade peruana, como Dominación y cultura. Lo cholo y el conflicto cultural en el Perú, de 1980.
} 
meio da análise dos grupos que Flores Galindo identificava como centrais na estrutura de classe desse tempo: a aristocracia colonial e a plebe urbana”.

A abordagem das classes sociais apresenta os traços típicos das concepções historiográficas de Flores Galindo, não se limitando a um tratamento marxista tradicional do conceito de classe e, portanto, não as reconhecendo somente em virtude de sua posse ou não dos meios de produção. Desta forma, a imagem construída sobre esta plebe está longe de configurar-se como um bloco único, formado por despossuídos e, por isso, apresenta-se como uma estrutura heterogênea, composta por diferentes setores sociais e referenciais culturais. Esta concepção de classe utilizada por Flores Galindo lhe permitiu compreender a plebe dentro de sua heterogeneidade e conflitos internos. Portanto, era formada por diferentes estratos étnicos, econômicos e culturais da sociedade: negros, brancos, indígenas, mestiços, escravos, ladrões, padeiros, trabalhadores temporários, camponeses, "vagabundos”, entre outros. Além da percepção das diferenças, o que fica claro é a desunião da plebe, fato que acabou por resultar em uma série de enfrentamentos e conflitos corporais e simbólicos internos. Na análise do autor, quase sempre não foi o “explorador” o adversário das plebes em suas contendas, mas sim um membro de outro segmento da mesma "classe explorada”, como demonstrava o claro desacordo entre negros e indígenas na época colonial. Para Flores Galindo, a falta de coesão fez com que os “plebeus” gastassem suas energias lutando entre si, ao invés de se mobilizarem contra os mecanismos de dominação estabelecidos pela aristocracia limenha oitocentista e, por isso, ainda segundo Aguirre (2007, p. 27-28), “esta sucessão interminável de enfrentamentos tornou virtualmente impossível a emergência de um projeto de coesão que permitisse desafiar o poder da aristocracia colonial”.

Assim como a plebe, a aristocracia também não se apresentava como uma estrutura homogênea e coesa. Ao longo dos últimos anos do vice-reinado do Peru, a elite mercantil tentou se estabelecer legitimamente como a liderança aristocrática limenha. "É uma aristocracia numerosa, porém jovem, sem vinculações diretas com o aparato produtivo (se interessa marginalmente no investimento em manufatura e mineração) e que, por isso mesmo, possui raízes fracas que a sustentam neste país [...]” (FLORES GALINDO, 1984, p. 230). Ao mesmo tempo em que se organizava enquanto classe dominante sofreu com as constantes crises produtivas provocadas pelo fim da ordem colonial, com as reformas bourbônicas que interferiram na lógica mercantil e com o início de um intenso ciclo de revoltas camponesas. Esta fragmentação social e a instabilidade política, não permitiram à aristocracia limenha se estabelecer legitimamente como classe dominante nem, tampouco, construir elementos administrativos e sociais que garantissem o seu domínio. Por conta disso, recorreu 
constantemente à construção de um discurso racista e à violência como forma de enaltecer e garantir sua soberania. Ocorre que, o uso da força, enquanto reflexo de sua insegurança de “classe” fragmentada e vulnerável, se converteu em um instrumento de prevenção e não de reação aos movimentos sociais. Por isso, “a violência tinha uma função exemplificadora: não se exercia recatadamente, em lugares reservados, longe dos curiosos. Ao contrário: o cenário preferido era a praça principal da cidade” (FLORES GALINDO, 1984, p. 149). A praça, mais do que o lugar de encontro da sociedade colonial em Lima, era o espaço próprio da plebe.

Vale ressaltar que a consciência de sua debilidade e o temor de possíveis levantes futuros restringiu a aristocracia ao mundo privado e, em oposição, o universo público acabou sendo dominado pela plebe. Por isso, Lima se assemelhava “[...] à cidade das grades. Elas separavam com nitidez a aristocracia, cuja vida familiar transcorria com mais frequência nos cômodos interiores e salas de jantares, da plebe que invadia as praças e as ruas da cidade [...] (FLORES GALINDO, 1984, p. 79)”. Para Flores Galindo, o resultado dessa relação de tumulto interno verificado junto à plebe limenha do século XIX, bem como a ausência de uma elite capaz de atuar de maneira protagonista, resultou na impossibilidade de uma revolução de independência, tanto semeada entre os populares, em reação à exploração, quanto como um projeto emancipador das elites. De outra forma, condenou a cidade a manter esta dicotomia flagrante entre o mundo da aristocracia e a segregação da plebe. Esta organização aristocrática da cidade de Lima apenas começaria a cair com o crescimento do processo de migração iniciado em 1946, data da formação da primeira barriada em Lima, a Cerro Sán Cosme como vimos anteriormente.

No entanto, a cholificação de Lima, o transbordamento popular visto na década de 1980 e a superação das estruturas aristocráticas ainda não teriam sido suficientes para abolir o racismo e a segregação social nem, tampouco, criar um sentido de coletividade entre a classe dominada que vivia nas barriadas da cidade de Lima. É questionando esta realidade que Flores Galindo encerrou seu livro. De acordo com o último parágrafo do livro,

Em certa maneira, o argumento deste livro poderia resumir-se negativamente. As circunstâncias que explicam por que não teve lugar uma revolução. A imbricação entre situação colonial, exploração econômica e segregação étnica edificou uma sociedade, ainda que soe paradoxo, tão violenta como estável. Em Lima não se conseguiu romper esse brutal equilíbrio que houvera permitido produzir uma revolução. [...] Desde Lima, por tudo isso, o ocaso da ordem colonial e da independência, na memória coletiva, aparecem como uma oportunidade perdida. Com efeito, desapareceu a aristocracia, porém a plebe - junto com ela os camponeses do interior - persistiram em sua condição. Para utilizar uma imagem do século passado: o mundo seguiu direito e ainda continuamos imaginando como 
colocá-lo ao revés. Um desafio onde o passado se confunde com o futuro, ainda esperando um desenlace diferente (FLORES GALINDO, 1984, p. 236).

Neste ponto, podemos nos questionar: o que separa a Lima dos séculos XVIII e XIX apresentada em Aristocracia y Plebe e a Lima vivida pelo autor em seu cotidiano da década de 1980? Assim como aquela a aristocracia de seu tempo se restringia ao mundo privado e ao mundo das instituições oficiais, enquanto a plebe continuava marginalizada nas barriadas e dominando o espaço público, o mundo informal. Por outro lado, a aristocracia se via acuada pelos ataques senderistas e, por isso, recorria à violência como forma de assegurar sua condição aristocrática e garantir a permanência do status quo. É uma classe dominante que, assim como aquela do passado, também por conta das constantes crises econômicas, não conseguia se estabelecer enquanto hegemônica e não fazia valer o seu discurso de poder, ou mesmo o seu projeto de nação.

O mesmo ocorre com relação à plebe que se fragmentava devido aos vários referenciais culturais vindos de seus lugares de origem, cuja quantidade ultrapassava o número de cinco mil comunidades indígenas diferentes. Da mesma forma, não aceitava a visão de mundo andino proposta pelo Sendero - que teoricamente representa uma oposição ao mundo formal da aristocracia - e, por isso, se constituiu em força de apoio ao exército no combate ao senderismo. Tratava-se de uma plebe que, assim como aquela do passado, via os verdadeiros inimigos nos segmentos de sua estrutura e não na própria aristocracia, como demonstravam os estudos sobre os conflitos cholos e criollos nos tugúrios.

A temática do migrante também apareceu de maneira bastante contundente nos últimos trabalhos de Alberto Flores Galindo antes de sua morte em 1990. É sobre este tema que discutiu com Hernando de Soto ao comentar o livro El otro Sendero. Em um artigo de 1988, sugestivamente intitulado de Los caballos de los conquistadores, otra vez, Flores Galindo questionou a visão de Soto a respeito do papel dos informais na sociedade limenha.

Como já abordamos, El otro sendero estava preocupado em discutir a questão da falência do modelo de Estado e a necessidade de se diminuir a informalidade incorporando-a na dinâmica oficial do mundo do capital. Para de Soto, o migrante, maioria absoluta entre os trabalhadores informais da cidade de Lima, poderia se converter na exemplificação do que se consagrou chamar de self made man. Uma vez inseridos na lógica do mercado e deixando para trás o seu passado tradicional, se apresentariam como fomento ao impulso econômico que o país precisava. Enquanto migrante, valorizou-se os esforços individuais que o levaram a 
abandonar uma realidade de pobreza em busca de melhores condições de vida, apostando nesta imagem para a construção de um modelo econômico exitoso.

Justamente por isso Flores Galindo elaborou o artigo que critica de Soto e seu livro. A questão central de seu texto é a leitura produzida em El Otro Sendero a respeito dos informais. Para Flores Galindo, uma análise sobre o trabalho informal em Lima deve superar os limites estatísticos e econômicos do impacto da migração. Segundo o autor, em uma cidade marcada pelo racismo a condição étnica de um migrante deve ser o elemento primordial de uma análise. Por isso, não se trata tão somente de migrantes, mas, sobretudo, migrantes mestiços.

Os informais não são somente migrantes. São também, como sabe qualquer um que caminhe por Lima, em sua maioria mestiços e devem suportar o menosprezo racial cotidiano e as travas da mobilidade que existem em uma sociedade onde as classes sociais, em especial as dominantes, recorreram a critérios étnicos para distinguir ricos e pobres. [...] Porém esses conflitos são omitidos porque para Hernando de Soto interessa propor justamente um terreno de encontro entre dominantes e dominados: todos são empresários (FLORES GALINDO, 1988, p. 201-202).

Na leitura de Flores Galindo, o tema dos informais não é somente uma problemática econômica, mas, antes de tudo, reflexo de uma condição cultural. A dualidade entre formalidade e informalidade ganhou traços dramáticos na década de 1980 não apenas por conta do agravamento da crise, mas, também, por robustecer o sentimento racista de uma cidade que, ao longo de sua história, produziu a segregação de grupos sociais. Podemos dizer que a formalidade era o novo nome da aristocracia, bem como e a informalidade representava a plebe.

De outra maneira, Flores Galindo defendia que, ainda que gerasse uma cidade caótica, os movimentos migratórios não possuíam um fluxo tão desordenado como teria interpretado de Soto. As relações de continuidade entre migrantes e suas comunidades de origem, produziam a formação de “clubes de convivência” que já articulavam cerca de 50\% da totalidade dos migrantes residentes em Lima, como mencionamos anteriormente. Esta realidade demonstraria que não se tratavam de homens movidos tão somente pelo esforço individual, mas de maneira contrária, que apostavam na força de "respostas coletivas” para a solução de seus problemas. Por isso, o trabalho de Hernando de Soto, poderia ser entendido como "um livro ideológico sim, em que os dados somente corroboram as ideias elaboradas de antemão” (FLORES GALINDO, 1988, p. 205).

A solução dos problemas de Lima, referentes ao encontro conflituoso entre Serra e Costa, provocados pelas migrações, são também abordadas em outro artigo intitulado Lima: 
crónica de un deterioro de 1985. Neste texto dedicado a comentar o livro Memoria y utopía de la vieja Lima, de César Pacheco Vélez, Flores Galindo aborda o problema da separação classista da seguinte forma:

É difícil que em uma cidade como esta os provincianos e os migrantes se sintam acolhidos e integrados: se vêm obrigados a congregarem entre eles, a buscar nas zonas marginais lugares de reunião, para formar instituições que os agrupem, como antes fizeram os negros ou índios em suas confrarias. Obrigados a viver na defensiva, não se sentem necessariamente convocados a preservar uma cidade que não identificam como sua. [...] ao meu modo de ver, Lima não é o resultado da mestiçagem e do encontro harmônico das tradições, porém isso não significa negar que no futuro possam ser um instrumento cabal para que o país se reencontre consigo mesmo (FLORES GALINDO, 2007, p. 169-171) ${ }^{10}$.

Assim como na crítica a de Soto, neste artigo, Flores Galindo aposta na validade de projetos coletivos como força capaz de gerar coesão e não na lógica liberal do “individualismo solidário”. Da mesma forma, recorre àquela imagem da Lima de Aristocracia y Plebe, onde a plebe se dividia em blocos sem comunicação. Neste sentido, a superação de qualquer dualidade (mundo informal/mundo formal, Costa/Serra, criollo/cholo) passaria, sem dúvida, por sua reflexão em torno da realidade observada cotidianamente na cidade de Lima.

O Peru convulsionado, resultante desses tempos de pragas e da crise econômica podia ser visto todos os dias nas ruas de Lima. A capital peruana era, portanto, a representação melhor acabada da falta de uma identidade coletiva que possibilitasse ser vista de maneira homogênea e não cindida. De qualquer maneira, ainda que propusessem saídas para a superação da dualidade, é interessante notarmos que, tanto Matos Mar, quanto de Soto e Flores Galindo continuaram a se utilizar da chave interpretativa criada sobre a cidade de Lima, ainda na década de 1950, seja com o binômio oficial/real, forma/informal ou aristocracia/plebe. A resignificação dessa chave explicativa por autores na década de 1980 nos leva a pensar que, mesmo com os processos migratórios, Andes e Costa continuaram divididos no imaginário peruano e em suas representações sobre a cidade de Lima, ainda que ambos já ocupassem o mesmo espaço ${ }^{11}$.

\footnotetext{
${ }^{10}$ O livro de César Pacheco Vélez era dedicado a estudar as transformações arquitetônicas na cidade de Lima decorrentes das mudanças provocadas pelo aumento populacional. Segundo analisava Pacheco, o centro velho de Lima estava perdendo seus principais prédios e referenciais históricos.

${ }^{11} \mathrm{Um}$ autor desse período que diverge dessa compreensão dicotômica foi Carlos Ivan Degregori. Ele, junto com outros autores, propôs uma interpretação dos conflitos sociais internos das barriadas como sendo o surgimento de uma cidadania moderna e de táticas de negociações para a conquista de direitos concebidos dentro de uma interpretação marxista heterodoxa dos direitos humanos. Ver: DEGREGORI, Carlos Iván; BLONDET, Cecilia; LYNCH, Nicolás. Conquistadores de un nuevo mundo. De invasores a ciudadanos en San Martin de Porras. Lima: IEP, 1986.
} 
Pensar Lima enquanto uma cidade cindida, como propôs as ciências sociais peruana entre as décadas de 1950 e 1980, nos ajuda a compreender de onde vem tanta reprovação à sua estética e à ausência de beleza. Talvez a feiúra de Lima relatada ao longo dos últimos cinco séculos passe por esta falta de identidade sobre si que acaba por se representar em sua arquitetura e sua urbanização. Se em um primeiro momento a cidade busca construir uma imagem de si que seja estrangeira ao seu lugar espacial, num último momento procura sustentar uma imagem aristocrática que não representa mais a realidade. Vê-se assim, uma cidade ainda afetada pela avalanche iniciada na década de 1950, mas que insiste em negá-la.

\title{
Lima, a City between the Aristocracy and the Commoners (1950-1980)
}

\begin{abstract}
The city of Lima has undergone serious changes over the past sixty years. Until the middle of the last century, Lima retained an urban structure similar to that built in the 18th century, during the final decades of its colonial period. This reality began to change with the abrupt onset of migration from the mountain ranges to the coast in 1946. However, rather than changes in its urban plan, Lima underwent a ethnic and social reconfiguration that would bring new color and new cultural and behavioral norms to the Peruvian capital. The arrival of migrants to the city caused a conservative reaction in the local elites, but it also sparked a need for the intelligentsia to develop new ways of thinking about the place of migrants in the space of the city, and on the other hand, to create new representations of the city itself. From being a city isolated from the rest of the country, Lima came to live with a range of cultural and ethnic references. It did so, however, without creating greater opportunities for the integration of the masses within the urban and social logic of the city, thus making clear the separation between the aristocracy and the general populace.
\end{abstract}

Key-words: Lima. Migrations. Social Science.

\section{Referências}

ADRIANZÉN, Alberto (Ed.). Pensamiento político peruano: 1930 - 1968. Lima: Desco Centro de Estudios y Promoción del Desarrollo, 1990.

AGUIRRE, Carlos. Aristocracia y Plebe. In: LÓPEZ JIMÉNEZ, Sinesio (dir). Homenaje a Alberto Flores Galindo: otro mundo es posible. Libros \& Artes. Lima: Biblioteca Nacional del Perú, 2005.

ALTAMIRANO, Teófilo. Estructuras Regionales, migración y formación de Asociaciones Regionales en Lima Metropolitana. Lima: PUCP, 1977.

ALVOJIN, Cristóbal; HERNANDEZ, Max; SAGASTI, Francisco. Los 50 Libros que Todo Peruano Culto Debe Leer. Lima: Caretas/PUCP, 2000. 
COLLIER, David. "Los Pueblos Jóvenes y la Adaptación de los migrantes al ambiente urbano limeño”. In: Estudios Andinos, ano 3, vol III, n. 3, Centro de Estudios Latinoamericanos, Universidad de Pitsburg, 1973

. Barriadas y Elites. De Odría a Velasco. Lima: IEP, 1978.

CONTRERAS, Carlos; CUETO, Marcos. Historia del Perú contemporáneo. 4. ed. Lima: IEP, 2007.

DE SOTO, Hernando. El otro Sendero. Lima: Instituto Libertad y Democracia, 1986.

DEGREGORI, Carlos Iván; BLONDET, Cecilia; LYNCH, Nicolás. Conquistadores de un nuevo mundo. De invasores a ciudadanos en San Martin de Porras. Lima: IEP, 1986.

FLORES GALINDO, Alberto. Aristocracia y Plebe. Lima, 1760 - 1830. Lima: Mosca Azul Editores, 1984. SUR, 2007.

. Lima: crónica de un deterioro. In: . Obras Completas. Tomo VI. Lima: . Los caballos de los conquistadores, otra vez. In: Lima: Caballo Rojo, 1988. . Tiempos de Plagas.

FRANCO, Carlos. Exploraciones en "otra modernidad”: de la migración a la plebe urbana. In: URBANO, Henrique (comp). Modernidad en los Andes. Lima: Centro Bartolomé de las Casas, 1991, p. 193-194.

JONGKIND, F. “La supuesta funcionalidad de los clubes regionales en Lima, Perú”. In: Boletín de Estudios Latinoamericanos, n. 11, University of Amsterdam, Holanda, 1971.

LLORÉNS, José Antonio. "Voces provincianas en Lima: migrantes andinos y comunicación radial”. In: Revista Peruana de Ciencias Sociales. Vol 2, n. 1, Lima, 1990.

QUIJANO, Anibal. El “movimiento indígena” y las cuestiones pendientes en América Latina. Disponível em: <http://www.democraciasur.com/regional/QuijanoMovIndigenaAL.htm>. Acesso em: 27 jun. 2008.

MANGIN, Willian. “Clube de provincianos en Lima”. In: Estudios sobre la Cultura del Perú. Lima: UNMSM, 1964.

MATOS MAR, José. Desborde Popular y Crisis del Estado: el nuevo rostro del Perú en La década de 1980. Lima: Concytec, 1988.

“Migración y urbanización. Las barriadas limeñas: un caso de integración a la vida urbana. In: HAUSER, Philip M. La Urbanización en América Latina. Buenos Aires: Solar/Hachette, 1959.

PINHEIRO, Marcos Sorrilha. A Historiografia Revolucionária: Alberto Flores Galindo e a nueva historia Peruana (1970-1980). Revista Eletrônica da ANPHLAC, v. 9, p. 10, 2010. 
SANDOVAL, Pablo. Lo rostros cambiantes de la ciudad: cultura urbana y antropología en el Peru. In: DEGREGORI, Carlos Iván (ed.). No Hay País Más Diverso: compendio de antropología peruana. Lima: Red para el Desarrollo de las Ciencias Sociales en el Perú, 2000, p. 279.

SOARES, Gabriela Pellegrino. Projetos Políticos de Modernização e Reforma no Peru: 19501975. São Paulo: Annablume/FAPESP, 2000.

Recebido em: 28/02/2011

Aprovado em: 01/04/2011 